\title{
Enhancing the Viability Rate of Probiotic by Co-Encapsulating with Prebiotic in Alginate Microcapsules Supplemented to Cupcake Production
}

\author{
Lieu My Dong ${ }^{1 *}$, Nguyen Thien Luan ${ }^{1}$, and Dang Thi Kim Thuy ${ }^{2}$ \\ ${ }^{1}$ Faculty of Food Science and Technology, Ho Chi Minh City University of Food Industry, Ho Chi Minh City, Vietnam \\ ${ }^{2}$ Department of Plain Cell Technology, Institute of Tropical Biology, Ho Chi Minh City, Vietnam
}

Received: October 30, 2019 / Revised: January 3, 2020 / Accepted: January 6, 2020

\begin{abstract}
The objective of the study was to assess the survival of microencapsulated Lactobacillus plantarum ATCC8014 produced using the emulsion technique in alginate gel combined with pectin and maltodextrin components. The microcapsules were then added to cupcake dough that was further baked at $200{ }^{\circ} \mathrm{C}$ for $12 \mathrm{~min}$. The viability of $L$. plantarum was assessed during baking and the 10 days of storage at $4^{\circ} \mathrm{C}$ as well as in simulated gastrointestinal conditions. In addition, yeast-mold and water activity were investigated. After baking, the samples with microencapsulated L. plantarum contained more than 5 log CFU/g, which was higher compared to the bacterial concentration of the control samples. The concentration of $L$. plantarum was more than $6 \operatorname{logs}$ CFU/g after the end of the storage; therefore, the probiotic functioned as a biopreservative in the cake. The prebiotic component strengthened the microcapsules network and helped protect the viability of $L$. plantarum in simulated gastric fluid (SGF) and simulated intestinal fluid (SIF) media. The results show that the addition of $L$. plantarum microencapsules did not affect the sensory scores of the cupcake while ensuring the viability of the probiotic during baking and storing.
\end{abstract}

Keywords: Cupcake, baking process, Lactobacillus plantarum, microencapsulation, prebiotic

\section{Introduction}

For decades, there has been a trend of producing functional foods containing probiotic bacteria [1]. Besides, interest in food ingredients on health have led to many functional foods containing such ingredients is available on the market [2], such as food products and supplements containing probiotic bacteria. Probiotics have been defined as microbial food supplements with beneficial effects on consumers [3]. There have been many studies of LAB species, in which Lactobacillus plantarum ATCC 8014 has been believed to help preserve the function of epithelial barrier and inhibit inflammation

\section{*Corresponding author}

Tel: +84-98-996-1848

E-mail: lieudong289@gmail.com

○ 2020, The Korean Society for Microbiology and Biotechnology by affecting the signaling pathway in the intestinal epithelium of human [4] and ability of bacteriocin production, and had a wide inhibitory effect on both negative and positive Gram harmful bacteria [5]. However, the viability of L. plantarum ATCC8014 under the impact of high temperature in the food production process was poorly reported.

Foodstuff is the most friendly way to consume probiotics, therefore many studies on making a lot of choices about how to combine probiotics in a multitude of foods [6]. But it is worth noting that most of the probiotic supplement foods on the market are made from dairy sources, such as ice cream, cheese, yogurt, and more. Meanwhile, the demand for non-dairy products is increasing according to vegetarianism or health issues related to dairy products such as lactose intolerance, allergies with milk protein and blood cholesterol control 
[7]. Therefore, probiotic bakery products contained probiotic microorganism is considered a new trend as well as diversify choice for probiotic supplement products. However, studies on the enrichment of probiotic included in baked products were still limited because these products are baked at high temperatures, where the probiotic life was lost [8]. Consequently, it is considered a technology solution that helps probiotic bacteria beyond this limit in which the microencapsulation technique such as spray drying, emulsion, extrusion methods achieved more attention. The purpose of microencapsulation-technique is to help protect the core material from the external environment [9], and this protective effect has been demonstrated on probiotics $[10,11]$. However, if considered the baking process, the encapsulated probiotic by the spray-drying method must undergo two heating times. Therefore, there needs an alternative encapsulating method without much influence on cell enumeration, such as extrusion or emulsion methods. However, capsules obtained from the extrusion method is large that affect the sensory and cause difficulty swallowing when added to food. So the goal of the microencapsulation technique today that create micron-sized microcapsules [12] but still maintain the minimum of required probiotic counting [13]. In this respect, encapsulation by emulsion method is considered as a reasonable solution while overcoming the limitations of the extrusion method but still maintaining its advantages such as ease, low cost and has little impact on the probiotic viability. In addition, choosing a suitable carrier also contributes to maintaining probiotic survival. Alginate was known to be the most active polymer and was widely used in previous studies to show that the ability to protect probiotic bacteria productivity [14, 15]. Microcapsules of maltodextrin and alginate have been shown to support probiotic survival during long storage [16]. Another wall material, pectin, has also been shown to be a potential material for probiotic-contained products by helping them to be stable and a suitable micro-environment for cell growth [17]. Though these properties were interesting, there are no data about investigating the protective efficiency of these three types of wall materials by the emulsion method. Therefore, this study aimed to investigate the protective ability of L. plantrum ATCC 8014 by emulsion method with calcium-alginate as the main carrier and auxiliary components contained with maltodextrin and pectin. The preparations added to the process of creating cupcakes and evaluated the probiotic viability during cupcake baking, cold storage, and testing in simulated gastric digestion. The spoilage of the cake was also considered.

\section{Material and Methods}

\section{Probiotic strain}

Lactobacillus plantarum ATCC 8014 strain was cultured in $10 \mathrm{ml}$ of MRS broth at $37^{\circ} \mathrm{C}$ for $26 \mathrm{~h}$ before being transferred to $90 \mathrm{ml}$ of MRS broth (Himedia, Mumbai, India) and Alginate, maltodextrin, pepsin, and beef bile were purchased from Himedia Company incubated under the same conditions. Biomass was collected by centrifuging and used for the next experiments.

\section{Microencapsulation}

The emulsion process was carried out in following steps: $10 \mathrm{ml}$ of fresh biomass mixed with $40 \mathrm{ml}$ of wall material (w/v) (including $2 \%$ alginate -A samples; $2 \%$ alginate - $1 \%$ maltodextrin -AM samples; $2 \%$ alginate $1 \%$ pectin -AP samples; $2 \%$ alginate $-0.5 \%$ maltodextrin - $0.5 \%$ pectin -APM samples), then the mixture was added $50 \mathrm{ml}$ of canola oil with $0.1 \%$ (v/v) Tween 80 and stirred for $10 \mathrm{~min}$ to allow emulsification and encapsulation to occur. Then, $50 \mathrm{ml}$ of $0.1 \mathrm{M} \mathrm{CaCl}_{2}$ was added quickly down the side of the beaker to break the emulsion. The capsules were harvested from the solution by centrifugation at $5000 \mathrm{rpm}$ for $10 \mathrm{~min}$.

\section{Preparing Cupcake dough}

Ingredients for making cupcakes include multi-purpose flour, icing sugar, eggs, cooking oil, mixed in with 1:1:0.8:0.8 (w/w/w/w) respectively. Vanilla and baking powder are added at $0.1 \%(\mathrm{w} / \mathrm{w})$, conducting mixing until homogeneous. Finally, fresh microcapsules $(7 \% \mathrm{w} / \mathrm{w})$ were added and mixed well for 5 min until homogeneously. A similar treatment was carried out in the sample containing free L. plantarum cells. Then, the mix was spread 50 grams into the tin and baking at $200^{\circ} \mathrm{C}$ for 12 min. After baking, the cakes were cooled down at room temperature before being taken for analysis. The enumeration of probiotic bacteria is enumerated before and after baking. 


\section{Refrigerating storage}

Viability of $L$. plantarum during refrigerated storage. The cupcake samples were stored in aseptic plastic bags at $4{ }^{\circ} \mathrm{C}$ for ten days. After every 2 days, each sample was analyzed to determine the viability of probiotic in cakes under cold storage conditions.

Water activity value $\left(a_{w}\right)$ changing and yeast - mold growth in the cupcake. The change in water activity $\left(\mathrm{a}_{\mathrm{w}}\right)$ of the cake in storage time was determined according to ISO 21807: 2004 [18]. The samples were placed in the cuvette and measured by EZ - 200 (Freund, Japan) at $25{ }^{\circ} \mathrm{C}$. The total number of yeast - mold spores were quantified according to ISO 21527-1: 2008 [19], whereby the sample was diluted in isotonic saline solution before being plated on DRBC medium. Petri dishes have been incubated under aerobic conditions at $30^{\circ} \mathrm{C} \pm 1{ }^{\circ} \mathrm{C}$ for 5 days.

\section{The viability of L. plantarum in SGF and SIF medium after storage}

10-gram (inside part of the cupcake) of samples was incubated in $90 \mathrm{ml}$ of the simulated gastric fluid (SGF) medium $(9 \mathrm{~g} / \mathrm{l} \mathrm{NaCl}+3 \mathrm{~g} / \mathrm{l}$ pepsin, adjusted to $\mathrm{pH} 2.5$ with $5 \mathrm{~N} \mathrm{HCl}$ ) at $37^{\circ} \mathrm{C}$, and shaking speed $100 \mathrm{rpm}$ for $120 \mathrm{~min}$. Then, the samples were transferred into the simulated gastric fluid (SIF) medium $(9 \mathrm{~g} / \mathrm{l} \mathrm{NaCl}, 3 \mathrm{~g} / \mathrm{l}$ beef bile, and adjusted $\mathrm{pH}$ to 6.5 by $5 \mathrm{M} \mathrm{NaOH}$ solution) by centrifugation and incubating for another $3 \mathrm{~h}$. The samples were taken at 2 and $5 \mathrm{~h}$ of incubation for enumeration. The viability of $L$. plantarum in the cupcake was immediately assayed by plating on MRS media.

\section{Enumerating probiotic population}

10-gram of cupcake samples was dissolved in the phosphate buffer 0.1 M (pH 7.0), followed by homogenizing in a stomacher (IUL-Spain) for $10 \mathrm{~min}$. The probiotic viability (CFU/g) was determined by spreading on MRSagar at $37^{\circ} \mathrm{C}$ for $48 \mathrm{~h}$. The process of similar samples for free cell samples.

\section{Sensory evaluation}

The "A, not A" test was conducted with the objective of determining if a significant difference existed between $A$ (cupcake without containing microcapsules) and 'not A' (cupcake containing microcapsules). The sensory evaluation was conducted by 30 assessors. Each assessor was familiarized with the sensory characteristics of the target sample ('A') from the cupcake without containing microcapsules and the nontarget sample ('not A') from the cupcake containing microcapsules having the best result in the study, and then received one test sample and asked to identify it as the 'target' or 'not the target'. The Chi-square test was used to determine whether consumers recognize the difference between the two samples.

\section{Static analysis}

All data obtained will be expressed as mean value $( \pm \mathrm{SD})$ of at least three replicates for each treatment using a Turkey test (SPSS20, IBM Inc.) and on Excel 2013 (Microsoft Inc.). The Chi-square test was used for sensory evaluation.

\section{Results and Discussion}

\section{Effect of baking process on the viability rate of $L$. plantarum}

After $12 \mathrm{~min}$ of baking, the temperature of crust increased $51^{\circ} \mathrm{C}$ from $58^{\circ} \mathrm{C}$ to $109^{\circ} \mathrm{C}$, respectively, the cake center increased $42^{\circ} \mathrm{C}$ from $42^{\circ} \mathrm{C}$ to $84^{\circ} \mathrm{C}$ (Fig. 1). After the baking process, free samples showed the lowest protection capacity $(p<0.05)$ decreased by $6.7 \pm 0.04 \log \mathrm{CFU}$ dramatically. The addition of pectin or maltodextrin has shown a significant increase in protection capacity $(p<0.05)$ compared to free samples with a reduction from $10.39 \pm 0.23$ to $5.65 \pm 0.25 \mathrm{log} \mathrm{CFU} / \mathrm{g}$ and from $10.31 \pm 0.18$ to $5.82 \pm 0.17 \mathrm{log} \mathrm{CFU} / \mathrm{g}$, respectively, but no significant difference $(p>0.05)$ between them. In par-

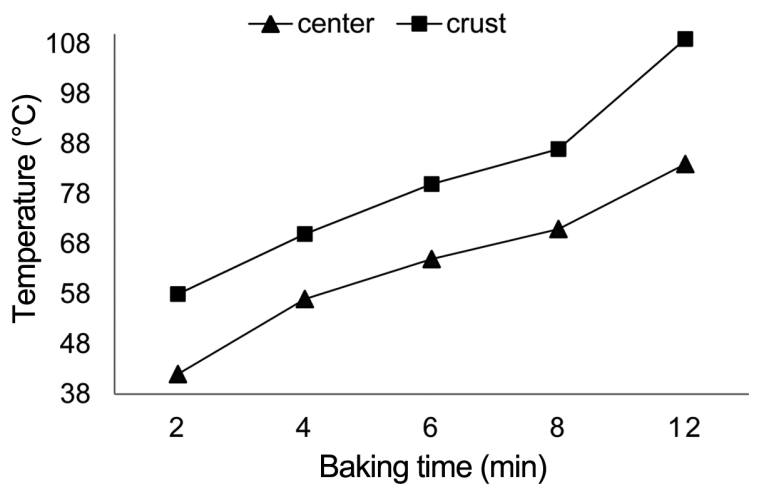

Fig. 1. Change of temperature in the cake center and crust during baking. 
ticular, the highest protection capacity was found in APM samples when the viability rate of $L$. plantarum cells in the microcapsules decreased from $10.52 \pm 0.18$ $\log \mathrm{CFU} / g$ to $5.98 \pm 0.22 \mathrm{log} \mathrm{CFU} / \mathrm{g}$ after baking for $12 \mathrm{~min}$. However, the L. plantarum viability was no significant difference among microencapsulated samples (Fig. 2).

The capacity protection of probiotic bacteria against the high temperature of carrier components has also been reported in previous studies. Anekella et al. made microencapsulation probiotic from maltodextrin by the spray-drying method which concluded that a heat level sub-lethal pre-treatment allowed cells to survive in this range and was only destroyed with the above output temperature at $92^{\circ} \mathrm{C}$ [10]. Similarly, Salar-Behzadi et al. demonstrated that pectin had capacity protection $B$. bifidum BB-12 cell membrane during spray drying and minimized cell destruction better than maltodextrin [20]. Another study by Seyedain-Ardabili et al. showed that encapsulated L. acidophilus and L. casei in alginate $2 \%(\mathrm{w} / \mathrm{v})$ and Hi-maize resistant starch $2 \%(\mathrm{w} / \mathrm{v})$ beads added to Hamburger cake showed the survival rate 4.2 $\log \mathrm{CFU} / \mathrm{g}$ and $3.5 \mathrm{log} \mathrm{CFU} / \mathrm{g}$ cells survived 1 day after baking $\left(180^{\circ} \mathrm{C}\right.$ for $\left.15 \mathrm{~min}\right)$, respectively, with an initial amount of about $11 \log \mathrm{CFU} / \mathrm{g}$ [21]. The author also noted that the temperature at the center of the hamburger between $93^{\circ} \mathrm{C}$ to $94^{\circ} \mathrm{C}$, which was higher than the $84^{\circ} \mathrm{C}$ in the center of the cupcake (Fig. 1) which had lower baking time but higher baking temperature than hamburger [21]. Lactobacillus rhamnosus R011 was encapsulated in WPI by freeze-drying method supplementing to biscuit showed that less than 2 log CFU/g cells were detected one day after baking with the center temperature and the surface temperature about $92^{\circ} \mathrm{C}$ and $98^{\circ} \mathrm{C}$ respectively [2]. Rajam et al. even recorded no Lactobacillus plantarum MTCC 5422 cells in the FOS + WPI beads in dried noodles after cooking, with about 6 to 8 log CFU cells lost in this process [22]. The results presented in Fig. 2 show that alginate combined with pectin and maltodextrin gave higher thermal resistance $(p<0.05)$ than the only alginate was used. In addition, it was particularly noteworthy that $4.65 \pm 0.17 \mathrm{log} \mathrm{CFU} / \mathrm{g}$ cells $L$. plantarum free form were surviving in cupcakes (Fig. 2). These suggests that not only the structural composition of the wall material but also the food matrix structure contributing to the protection of probiotic cells

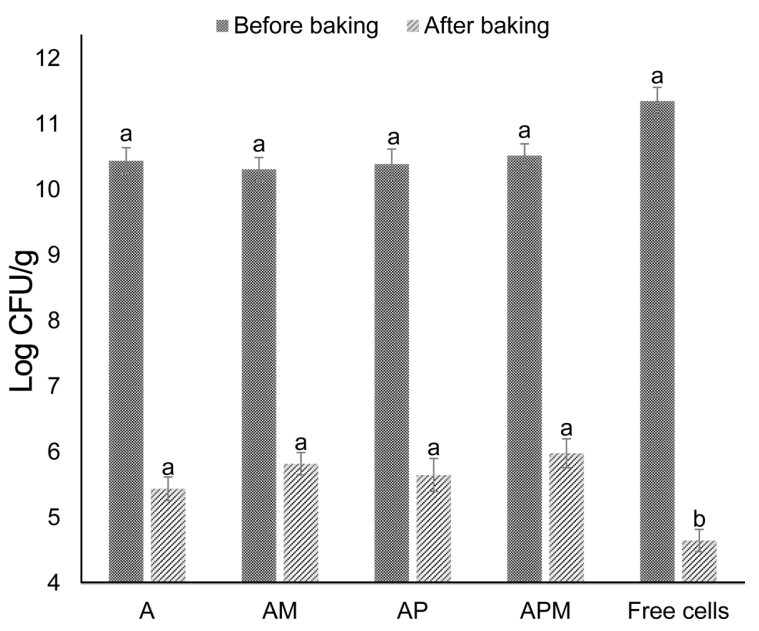

Fig. 2. The survival rate of free and encapsulated $L$. plantarum before and after baking process. A: alginate $2 \%, A M$ : alginate $2 \%+$ maltodextrin $1 \%$; AP: alginate $2 \%+$ pectin $1 \%$; APM: alginate $2 \%+$ maltodextrin $0.5 \%$ + pectin $0.5 \%$. Superscript letters $(a-b)$ above the error bars that are significantly different among samples $(p<0.05)$.

when exposed in harsh heating. Similarly, Malmo et al. investigated that microcapsules of L. reuteri DSM 17938 in food form helped maintain their survival rate better than the in vitro form after undergoing heat treatment at $180^{\circ} \mathrm{C}$ for $10 \mathrm{~min}$ [23]. This suggests that the microcapsule carrier as well as the food ingredient had impacted significantly on the viability rate of probiotic bacteria (Fig. 2).

\section{Survey of refrigerating storage}

The survival rate of $L$. plantarum during storage. The results show that cupcakes containing microcapsules AM, AP and APM all showed that L. plantarum viability had a tendency to increase slightly over 6 log CFU after 10 days of cold storage and reach the required minimum count [13]. The sample containing free cells also increased to $0.3 \log$ CFU after 10 days of storage. Especially, the cupcake containing calcium-alginate $(2 \% \mathrm{w} / \mathrm{v})$ product (A samples) reduced $0.29 \log$ CFU of L. plantarum, but no significant difference $(p>0.05)$ compared to the free cell samples.

The increase in the number of $L$. plantarum cells has shown that metabolism has occurred during cold storage. Avila-Reyes et al. have reported that the metabolism of probiotic bacteria in microcapsules still took place at $4^{\circ} \mathrm{C}$ [24]. Kraseakoopt et al. showed the growth 


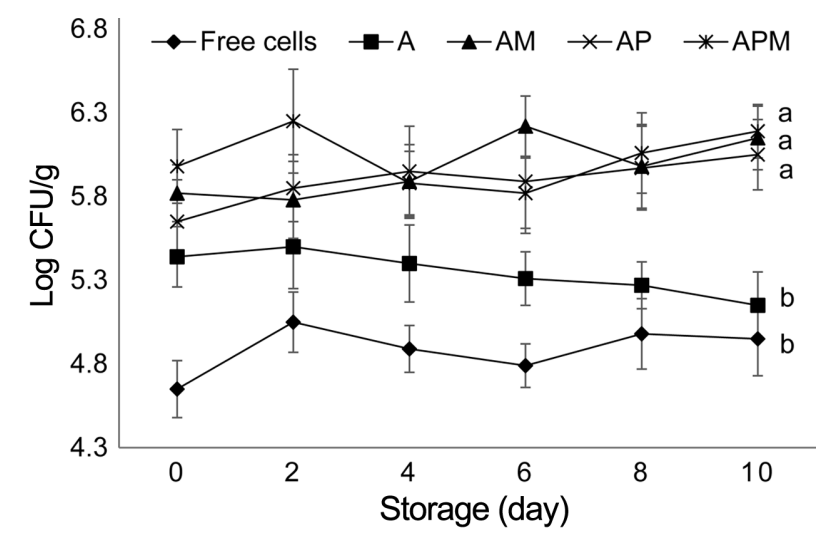

Fig. 3. The survival of $L$. plantarum during refrigerated $\left(4^{\circ} \mathrm{C}\right)$ storage period (10 day). A: alginate $2 \%$, AM: alginate $2 \%+$ maltodextrin 1\%; AP: alginate $2 \%$ + pectin $1 \%$; APM: alginate $2 \%+$ maltodextrin $0.5 \%+$ pectin $0.5 \%$. Superscript letter $(a-b)$ appeared at the last of each line that is significantly different $(p<0.05)$.

of $L$. acidophilus at $0.2 \log \mathrm{CFU}$ in calcium-alginate with FOS (fructo oligosaccharide) $0.3 \%(\mathrm{w} / \mathrm{v})$ beads added in orange juice preserved at $4{ }^{\circ} \mathrm{C}$ after 4 weeks of storage [25]. Similar to FOS, maltodextrin was also widely known as a prebiotic [10]. This protection has been proven, Sohail et al. showed that the double-layer spray drying microcapsules of $L$. acidophilus NCFM helped maintain $5.51 \log \mathrm{CFU} / \mathrm{g}$ after 6 months of storage at $4^{\circ} \mathrm{C}$ [16]. The presence of both prebiotic and probiotic formed a symbiotic system [7]. therefore L. plantarum seemed to have access to the carbon source for their development (Fig. 3). On the other hand, pectin was also recognized by many authors as a prebiotic [17]. Yeo et al. stated that the addition of maltodextrin and pectin increased the amount of probiotic in fermented soy milk [26]. Voo et al. 2010 reported that pectin was a potential carrier that helps probiotic cells reproduce stably and was a suitable micro-environment for cell growth [17]. Therefore, the absence of supplementation with maltodextrin and pectin were considered to significantly $(p<0.05)$ effect on the viability rate of the probiotic contained in the cake (Fig. 3). In addition, L. plantarum in the free cell form also had a slight growth from $4.65 \pm 0.17$ to $4.95 \pm 0.22 \log \mathrm{CFU} / \mathrm{g}$ (Fig. 3). This phenomenon can be explained by the fact that free probiotics have assimilated carbon sources from the cupcake. In addition, cryopreservation temperature $\left(4^{\circ} \mathrm{C}\right)$ also played an important factor that helps prolong the probiotics self-life during the storage period. Trabelsi et al. showed similar protection ability when L. plantarum TN8 was entrapped in alginate microcapsules coated with chitosan preserved in phosphate buffer ( $\mathrm{pH}$ 7.4), almost no change in the enumeration of probiotic cells at $4^{\circ} \mathrm{C}$ in 7-15 days of preservation [27]. But this was in contrast to the study of Zanjani et al. observed that the survival rate of $L$. casei in three samples: free cells, calcium alginate, and calcium alginate - corn resistant starch in cake cream tended to decrease continuously for 1 to 2 weeks at $4{ }^{\circ} \mathrm{C}$ [12]. This suggests that the type of carrier as well as the food ingredient had affected the viability of probiotic bacteria during the preservation of the cake. The results showed that the viability of $L$. plantarum was decreased rapidly after 10-day of storage. Besides, the sensory property of the cupcakes was getting a negative smell.

Change in $a_{w}$ value and the growth of yeast - mold during storage. The results showed that the water activity of the cake was on day 0 and day 10 ranged from

Table 1. The spoilage of cupcake sample monitored by the growth of yeast and mold during storage.

\begin{tabular}{ccccccc}
\hline \multirow{2}{*}{ Day } & \multicolumn{4}{c}{ Total number of yeast - mold (log CFU/g) } \\
\cline { 2 - 7 } & Without probiotic sample & Control sample & $\mathrm{A}$ & $\mathrm{AM}$ & $\mathrm{AP}$ & $\mathrm{AMP}$ \\
\hline 0 & $\mathrm{Na}$ & $\mathrm{Na}$ & $\mathrm{Na}$ & $\mathrm{Na}$ & $\mathrm{Na}$ & $\mathrm{Na}$ \\
2 & $\mathrm{Na}$ & $\mathrm{Na}$ & $\mathrm{Na}$ & $\mathrm{Na}$ & $\mathrm{Na}$ & $\mathrm{Na}$ \\
4 & $2.26 \pm 0.24$ & $\mathrm{Na}$ & $\mathrm{Na}$ & $\mathrm{Na}$ & $\mathrm{Na}$ & $\mathrm{Na}$ \\
6 & $2.96 \pm 0.28$ & $2.10 \pm 0.05$ & $2.42 \pm 0.25$ & $2.27 \pm 0.23$ & $2.37 \pm 0.24$ & $2.32 \pm 0.21$ \\
8 & $3.75 \pm 0.20$ & $2.57 \pm 0.21$ & $3.19 \pm 0.22$ & $2.97 \pm 0.18$ & $3.10 \pm 0.27$ & $2.82 \pm 0.23$ \\
10 & $5.25 \pm 0.31$ & $3.95 \pm 0.23$ & $4.58 \pm 0.36$ & $4.35 \pm 0.22$ & $4.48 \pm 0.26$ & $4.30 \pm 0.22$ \\
\hline
\end{tabular}

Na: below 2Log CFU/g.

Control sample: cupcake containing free probiotic cell, A: alginate $2 \%$, AM: alginate $2 \%+$ maltodextrin $1 \%$; AP: alginate $2 \%+$ pectin $1 \%$; APM: alginate $2 \%+$ maltodextrin $0.5 \%+$ pectin $0.5 \%)$. 
0.96-0.98 (data not shown). In the investigation of yeastmold growth in the cupcake, except for the control sample, the total yeast and mold count (over 2 log CFU/g) was only detected on the 6th day of storage (Table 1). On subsequent preservation days, total yeast and mold count in all cupcake samples increased, in which samples with $L$. plantarum added tended to be lower than control samples. Samples containing free probiotic cells had significantly lower yeast-mold $(p<0.05)$ than the control samples, but this difference was not significant when compared to other samples contained probiotic microcapsules (Table 1). In the previous study, Khalil et $a l$. found that the density of yeast-mold in the mayonnaise sample supplemented with Bifidobacterium was lower than that of non-supplementary mayonnaise samples [28]. This suggests that probiotic cells may have acted as a bio-preservation agent against the spoilage of the cake, which was shown to inhibit the growth of yeast-mold. The higher enumeration of mold in probiotic microcapsules samples compared to free samples may be due to L. plantarum being "entrapped" in the carrier matrix, leading to a lower inhibitory effect on mold than in free form (Table 1).

\section{Viability of $L$. plantarum in SGF and SIF treatment after storage}

The viability of encapsulated $L$. plantarum and free cells in SGF and SIF media is presented in Fig. 4. In the SGF medium, L. plantarum cells were provided signifi-

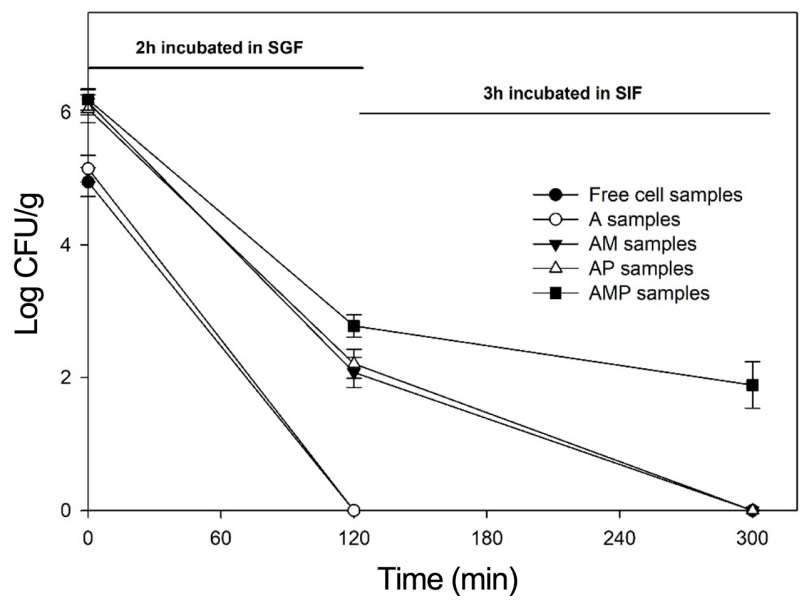

Fig. 4. The effect of SGF and SIF condition on the viability rate of free and encapsulated $L$. plantarum. A: alginate $2 \%$, AM: alginate $2 \%+$ maltodextrin $1 \%$; AP: alginate $2 \%$ + pectin $1 \%$; APM: alginate $2 \%+$ maltodextrin $0.5 \%+$ pectin 0.5 . cant protection $(p<0.05)$ when encapsulated in APM with $2.78 \pm 0.17 \log \mathrm{CFU} / \mathrm{g}$ cells survived and it was higher $(p<0.05)$ than AM or AP samples with the remaining cell enumerations of $2.08 \pm 0.23$ and $2.21 \pm$ $0.22 \log \mathrm{CFU} / \mathrm{g}$ cell survived after exposed in SGF, respectively. No $L$. plantarum cells were detected in sample A and free samples (Fig. 4). In the SIF treatment, after $3 \mathrm{~h}$ incubating, the viable cells were only recorded in the APM samples (Fig. 4). The results also indicated that the negative impact that the SGF medium causes on encapsulated $L$. plantarum was stronger than the SIF medium.

Under SGF conditions, the viability of $L$. plantarum in microcapsules supplemented with pectin or maltodextrin was higher in protective efficacy than alginate sample $2 \% \mathrm{w} / \mathrm{v}$ (A sample) (Fig. 4). Chen et al. suggested that the addition of prebiotic may help to limit the porous structure of the microbial composition [29]. This helped to strengthen the gel network structure and prevent the diffusion of acid (outside) into the microbial impact of probiotic life (Fig. 4). In addition, Ca-alginatepectin gel particles were thought to be dense and insoluble when exposing to an environment that had $\mathrm{pH}$ value was close to their $\mathrm{pK}_{\mathrm{a}}$ [17]. Fareez et al. showed that the survival rate of $L$. plantarum LAB12 in the alginatexanthan gum beads coated with chitosan reached $95 \%$ after 120 min of treatment under SGF conditions $(\mathrm{pH}$ 1.8, not containing pepsin) [30]. Meanwhile, Rajam et al. reported that about $30 \%$ of $L$. plantarum cells were detected in FOS microcapsules contained in noodles after treatment with SGF supplemented with $0.3 \%(v / v)$ pepsin after $2 \mathrm{~h}$ of treatment [22]. This may be due to the presence of pepsin in SGF affecting the protective effect of carriers. In addition, cryopreservation conditions can also increase the sensitivity of probiotic bacteria to low $\mathrm{pH}$ conditions. Sathyabama et al. reported that, during cryopreservation $\left(4^{\circ} \mathrm{C}\right)$, prebiotic components outside the microcapsules caused osmotic pressure on the probiotic inside [15].

Bile salts were thought to have chelating effects on the two valence ion bonds of alginate so they cause the microcapsules to break and release the cell out [23]. This has a disadvantaged effect on the survival of probiotics when they exposed to SIF directly. The results showed that the APM sample yielded the highest protection capacity although insignificant $(p>0.05)$ compared to A, 
AM, and AP (Fig. 4). Similarly, Ding and Shah showed that about $2 \log$ CFU encapsulated L. plantarum in alginate $3 \%(\mathrm{w} / \mathrm{v})$ were lost after $4 \mathrm{~h}$ incubation in SIF (bile $3 \% \mathrm{w} / \mathrm{v}$ ) [11]. However, Sandoval-Castilla et al. reported that the combination of prebiotic and alginate provided better protection of $L$. casei before bile salts than the substrate network of each individual carrier due to alginate in the grain variation reduced to some extent and the protective effect and both alginate and pectin make up a structured matrix, better resilience to acid and bile salts on microstructure characteristics of microcapsules [14]. The results obtained in Fig. 4 show that co-addition of pectin and maltodextrin in the process of creating alginate microcapsules (AMP sample) has significantly improved $(p<0.05)$ probiotic viability rate compared the others sample in the SGF condition, as well as in the SIF condition (Fig. 4). The result shows that the protective role of maltodextrin-pectin on $L$. plantarum in the adverse media.

\section{Sensory evaluation}

The sensory evaluation of comparison of the cupcake with and without the addition of microcapsules $(5 \% \mathrm{w} / \mathrm{w})$. The results showed that the Chi-square value of AM, $\mathrm{AP}$, and AMP samples were 2.40; 2.14; and 2.22 respectively, which indicated that the difference between these samples was not significant $(p>0.05)$ (Table 2).

The sensory evaluation is an important role in which sensory difference due to supplementation of microcapsules could lead to consumer rejection. The previous studies indicated that the amount, as well as the particle size of the microcapsules affecting the sensory properties of food products. Encapsulated Bifidobacterium longum in carrageenan particles adding into yogurt was made a significant difference compared to the control sample [31]. Whereas, cream-filled cakes containing microcapsules

Table 2. Comparison of Cupcake with and without the addition of microcapsules. Statistical differences are found when the Chi-square values are $\geq 3.8$.

\begin{tabular}{cc}
\hline Samples & Chi-square \\
\hline AM & 2.40 \\
AP & 2.14 \\
AMP & 2.22 \\
\hline
\end{tabular}

AM: alginate $2 \%+$ maltodextrin $1 \%$; AP: alginate $2 \%+$ pectin $1 \%$; APM: alginate $2 \%+$ maltodextrin $0.5 \%+$ pectin $0.5 \%$. (average size was $280 \mu \mathrm{m}$ ) or free cells of $L$. casei did not show a significant difference $(p>0.05)$ in the body and texture of the cream-filled cake [12]. Similarly, the same result was obtained in the present study (Table 2). The significant difference was found in the case of the cupcake containing more than $8 \%(\mathrm{w} / \mathrm{w})$ of microcapsules (data not shown). The results indicated that adding microencapsulation preparation would not affect the sensory of the cupcake as well as ensuring the viability of probiotic during baking and storing.

The results of the study showed that microencapsulation helped to improve the survival of $L$. plantarum during the baking process, in which the addition of the two components pectin and maltodextrin to the Caalginate microcapsule preparation process that delivered significant impact $(p<0.05)$ on the survival ability of Lactobacillus plantarum ATCC8014 during the baking process compared to the non-supplemented cupcake. The cake preservation process also showed that $L$. plantarum cell enumeration in all samples tended to increase after 10 days of storage at $4^{\circ} \mathrm{C}$ and reached the required minimum count (6-7 log CFU/g) in the supplemented prebiotic samples. With a high water activity value of $0.96-0.98$, spoilage of food was shown by a significant increase $(p<0.05)$ of the yeast and mold during storage. The total of yeast and mold in probiotic supplemented samples were reduced compared to samples without probiotic supplementation. Besides, the viability of $L$. plantarum was more sensitive to the SGF environment than SIF and microcapsule preparations for significantly higher protective effects. The simultaneous addition of pectin and maltodextrin in $\mathrm{Ca}$-alginate beads gave the best protection in SGF conditions, as well as in the SIF condition. Additionally, in the sensory evaluation, the difference between samples with (AM; AP and APM) or without microcapsules was not significant.

\section{Conflict of Interest}

The authors have no financial conflicts of interest to declare.

\section{References}

1. Burgain J, Gaiani C, Linder M, Scher J. 2011. Encapsulation of probiotic living cells: From laboratory scale to industrial applications. J. Food Eng. 104: 467-483.

2. Reid AA, Champagne C, Gardner N, Fustier P, Vuillemard J. 2007. 
Survival in food systems of Lactobacillus rhamnosus R011 microentrapped in whey protein gel particles. J. Food Sci. 72: M031M037.

3. Parvez S, Malik KA, Kang SAh, Kim HY. 2006. Probiotics and their fermented food products are beneficial for health. J. Appl. Microbiol. 100: 1171-1185.

4. Ko JS, Yang HR, Chang JY, Seo JK. 2007. Lactobacillus plantarum inhibits epithelial barrier dysfunction and interleukin-8 secretion induced by tumor necrosis factor-a. World J. Ggastroenterol. 13: 1962-1965.

5. Lash BW, Mysliwiec TH, Gourama H. 2005. Detection and partial characterization of a broad-range bacteriocin produced by Lactobacillus plantarum (ATCC 8014). Food Microbiol. 22: 199-204.

6. García-Ceja A, Mani-López E, Palou E, López-Malo A. 2015. Viability during refrigerated storage in selected food products and during simulated gastrointestinal conditions of individual and combined lactobacilli encapsulated in alginate or alginate-chitosan. LWT-Food Sci. Technol. 63: 482-489.

7. Majzoobi M, Aghdam MBK, Eskandari MH, Farahnaky A. 2019. Quality and microbial properties of symbiotic bread produced by straight dough and frozen part-baking methods. J. Text. Stud. 50: 165-171.

8. Arslan-Tontul S, Erbas M. 2017. Single and double layered microencapsulation of probiotics by spray drying and spray chilling. LWT-Food Sci. Technol. 81: 160-169.

9. Gibbs BF, Kermasha S, Alli I, Mulligan CN. 1999. Encapsulation in the food industry: a review. Int. J. Food Sci. Nutr. 50: 213-224.

10. Anekella K, Orsat V. 2013. Optimization of microencapsulation of probiotics in raspberry juice by spray drying. LWT-Food Sci. Technol. 50: 17-24.

11. Ding W, Shah N. 2007. Acid, bile, and heat tolerance of free and microencapsulated probiotic bacteria. J. Food Sci. 72: M446M450.

12. Zanjani MAK, Tarzi BG, Sharifan A, Mohammadi N, Bakhoda $H$, Madanipour MM. 2012. Microencapsulation of Lactobacillus casei with calcium alginate-resistant starch and evaluation of survival and sensory properties in cream-filled cake. Afr. J. Microbiol. Res. 6: 5511-5517.

13. Hotel ACP, Cordoba A. 2001. Health and nutritional properties of probiotics in food including powder milk with live lactic acid bacteria. Prevention 5: 1-10.

14. Sandoval-Castilla O, Lobato-Calleros C, García-Galindo H, AlvarezRamírez J, Vernon-Carter E. 2010. Textural properties of alginatepectin beads and survivability of entrapped Lb. casei in simulated gastrointestinal conditions and in yoghurt. Food Res. Int. 43: 111-117.

15. Sathyabama S, Vijayabharathi R. 2014. Co-encapsulation of probiotics with prebiotics on alginate matrix and its effect on viability in simulated gastric environment. LWT-Food Sci. Technol. 57: 419-425.

16. Sohail A, Turner MS, Coombes A, Bhandari B. 2013. The viability of Lactobacillus rhamnosus GG and Lactobacillus acidophilus NCFM following double encapsulation in alginate and maltodex- trin. Food Bioprocess Technol. 6: 2763-2769.

17. Voo W-P, Ravindra P, Tey BT, Chan E-S. 2011. Comparison of alginate and pectin based beads for production of poultry probiotic cells. J. Biosci. Bioeng. 111: 294-299.

18. I. 21807. Microbiology of food and animal feeding stuffs-determination of water activity. pp. 1-7, 2004.

19. I. 21527-1:2008, "21527-1 (2008)." Microbiology of food and animal feedings stuff-Horizontal method for the enumeration of yeasts and moulds-Part, vol. 1. pp. 1-8, 2008.

20. Salar-Behzadi $S$, Wu S, Toegel $S$, Hofrichter M, Altenburger I, Unger FM, et al. 2013. Impact of heat treatment and spray drying on cellular properties and culturability of Bifidobacterium bifidum BB-12. Food Res. Int. 54: 93-101.

21. Seyedain-Ardabili M, Sharifan A, Ghiassi Tarzi B. 2016. The production of synbiotic bread by microencapsulation. Food Technol. Biotechnol. 54: 52-59.

22. Rajam R, Kumar SB, Prabhasankar P, Anandharamakrishnan C. 2015. Microencapsulation of Lactobacillus plantarum MTCC 5422 in fructooligosaccharide and whey protein wall systems and its impact on noodle quality. J. Food Sci. Technol. 52: 4029-4041.

23. Malmo C, La Storia A, Mauriello G. 2013. Microencapsulation of Lactobacillus reuteri DSM 17938 cells coated in alginate beads with chitosan by spray drying to use as a probiotic cell in a chocolate soufflé. Food Bioprocess Technol. 6: 795-805.

24. Avila-Reyes SV, Garcia-Suarez FJ, Jiménez MT, San Martín-Gonzalez MF, Bello-Perez LA. 2014. Protection of L. rhamnosus by spraydrying using two prebiotics colloids to enhance the viability. Carbohydr. Polym. 102: 423-430.

25. Krasaekoopt W, Watcharapoka S. 2014. Effect of addition of inulin and galactooligosaccharide on the survival of microencapsulated probiotics in alginate beads coated with chitosan in simulated digestive system, yogurt and fruit juice. LWT-Food Sci. Technol. 57: 761-766.

26. Yeo SK, Liong MT. 2010. Effect of prebiotics on viability and growth characteristics of probiotics in soymilk. J. Sci. Food Agric. 90: $267-275$.

27. Trabelsi I, Bejar W, Ayadi D, Chouayekh H, Kammoun R, Bejar S, et al. 2013. Encapsulation in alginate and alginate coated-chitosan improved the survival of newly probiotic in oxgall and gastric juice. Int. J. Biol. Macromol. 61: 36-42.

28. Khalil AH, Mansour EH. 1998. Alginate encapsulated bifidobacteria survival in mayonnaise. J. Food Sci. 63: 702-705.

29. Chen KN, Chen MJ, Liu JR, Lin CW, Chiu HY. 2005. Optimization of incorporated prebiotics as coating materials for probiotic microencapsulation. J. Food Sci. 70: M260-M266.

30. Fareez IM, Lim SM, Mishra RK, Ramasamy K. 2015. Chitosan coated alginate-xanthan gum bead enhanced $\mathrm{pH}$ and thermotolerance of Lactobacillus plantarum LAB12. Int. J. Biol. Macromol. 72: 1419-1428.

31. Adhikari K, Mustapha A, Grün IU. 2003. Survival and metabolic activity of microencapsulated Bifidobacterium longum in stirred yogurt. J. Food Sci. 68: 275-280. 